\title{
The surgical treatment of rectal cancer in Poland. The findings of a multi-center observational study by the Polish Society of Surgical Oncology (PSSO-01)
}

\author{
Michał Jankowski ${ }^{1 *}$, Andrzej Rutkowski2*, Wojciech Zegarski ${ }^{1}$, Adam Majewski ${ }^{3}$, Marcin Zeman ${ }^{4}$, \\ Marek Mądrecki ${ }^{5}$, Wojciech Woźny ${ }^{6}$, Wiesław Kruszewski $7{ }^{7}{ }^{8}$, Grzegorz Celban ${ }^{9}$, Józef Kładny ${ }^{10}$, \\ Zbigniew Lorenc ${ }^{11}$, Bartosz Kapturkiewicz ${ }^{12}$, Marek Bębenek ${ }^{12}$, Mirosław Szura ${ }^{13}$, \\ Wojciech M. Wysocki ${ }^{14,15,16}$, Dawid Murawa ${ }^{17,18}$, Wojciech Polkowski ${ }^{19}$, Stanisław Głuszek20, \\ Józef Wróbel21, Tomasz Olesiński²
}

'Department of Surgical Oncology, Oncology Center - Prof Franciszek Lukaszczyk Memorial Hospital, Bydgoszcz, Poland ${ }^{2}$ Department of Gastroenterological Oncology, Maria Sklodowska-Curie National Research Institute of Oncology, Warsaw, Poland ${ }^{3}$ Specialist Hospital of Dr. Alfred Sokolowski, Walbrzych, Poland

${ }^{4}$ The Oncologic and Reconstructive Surgery Clinic, Maria Sklodowska-Curie National Research Institute of Oncology, Gliwice, Poland

${ }^{5}$ First Department of General and Oncological Surgery, Voivodeship Integrated Hospital in Plock, Plock, Poland ${ }^{6}$ First Department of General and Oncological Surgery, Voivodeship Hospital Centre of the Jelenia Gora Basin, Jelenia Gora, Poland 7Oncological Surgery Department, Gdynia Centre of Oncology, Polish Red Cross Memorial Maritime Hospital, Pomeranian Hospitals Ltd., Gdynia, Poland ${ }^{8}$ Division of Oncological Propedeutics, Medical University of Gdansk, Gdansk, Poland

${ }^{9}$ Department of Surgical Oncology, Jurassic Center of Oncology, Czestochowa, Poland

${ }^{10}$ Department of General and Oncological Surgery, Pomeranian Medical University, Szczecin, Poland

${ }^{1 " C l i n i c a l ~ D e p a r t m e n t ~ o f ~ G e n e r a l, ~ C o l o r e c t a l ~ a n d ~ T r a u m a ~ S u r g e r y, ~ S i l e s i a n ~ M e d i c a l ~ U n i v e r s i t y, ~ S o s n o w i e c, ~ P o l a n d ~}$

${ }^{12}$ Department of Surgery, Lower Silesian Oncological Centre, Wroclaw, Poland

${ }^{13}$ Department of Surgery, Institute of Physiotherapy, Faculty of Health Science, Jagiellonian University, Krakow, Poland

${ }^{14}$ Chair of Surgery, Faculty of Medicine and Health Sciences, Andrzej Frycz Modrzewski Krakow University, Krakow, Poland

${ }^{15}$ Department of General, Oncological and Vascular Surgery, $5^{\text {th }}$ Military Clinical Hospital in Krakow, Krakow, Poland

${ }^{16}$ Scientific Editorial Office, Maria Sklodowska-Curie National Research Institute of Oncology, Warsaw, Poland

${ }^{17}$ Chair of Surgery and Oncology, Collegium Medicum, University in Zielona Gora, Zielona Gora, Poland

${ }^{18}$ Department of General Surgery and Surgical Oncology, University Hospital in Zielona Gora, Zielona Gora, Poland

${ }^{19}$ Department of Surgical Oncology, Medical University of Lublin, Lublin, Poland

${ }^{20}$ Department of General, Oncological and Endocrinological Surgery, Collegium Medicum Jan Kochanowski University in Kielce, Kielce, Poland

${ }^{21}$ Beskid Oncology Center - John Paul II Municipal Hospital, Bielsko-Biala, Poland

* Michał Jankowski and Andrzej Rutkowski contributed equally to this work

Introduction. PSSO-01, a Polish prospective multi-center project on rectal cancer, started in 2016 with participation on a voluntary basis. This study evaluates the early outcome of the surgical treatment of rectal cancer in Poland according to hospital volume.

\section{How to cite:}

Jankowski M, Rutkowski A, Zegarski W, Majewski A, Zeman M, Mąrecki M, Woźny W, Kruszewski W, Celban G, Kładny J, Lorenc Z, Kapturkiewicz B, Bębenek M, Szura M, Wysocki WM., Murawa D, Polkowski W, Głuszek S, Wróbel J, Olesiński T. The surgical treatment of rectal cancer in Poland. The findings of a multi-center observational study by the Polish Society of Surgical Oncology (PSSO-01). NOWOTWORY J Oncol 2021; 71: 282-289. 
Material and methods. The dataset derives from 17 clinical centers registered in the PSSO-01 study. From 2016 to 2020, the data of 1,607 patients were collected. Taking into account the number of patients enrolled in the study, the centers were divided into three categories: high volume, medium volume, and low volume. Nominal variables were compared between different categories of centers using the chi-square test. The STROBE guidelines were used to guarantee the reporting of this observational study.

Results. More patients with metastatic disease were operated on in the low volume centers $(p=0.020)$. Neoadjuvant treatment was used in 35\%,52\%, and 66\% of patients operated on in low, medium, and high volume centers respectively $(p<0.001)$. Laparoscopic resection in medium volume centers was performed more often than in other centers $(p<0.001)$. The total rate of postoperative complications related to high, medium, and low centers was 22\%, 26\%, 18\% ( $p=0.044)$. One year following surgery, a stoma was present in $63 \%$ of patients. A defunctioning stoma following anterior resection was reversed in only 55\% of patients. Anastomotic leakage was the main reason for a non-reversal diverting stoma.

Conclusions. The representation of low volume centers in the PSSO-01 study was understated. However, the outcomes may show the actual situation of surgical treatment of rectal cancer in high and medium volume centers in Poland.

Key words: rectal cancer, surgery, volume center, stoma

\section{Introduction}

Every year, about 6,000 new cases of rectal cancer are recorded in Poland. Most of them require surgical treatment. Unfortunately, we neither have a nationwide registry that allows us to determine the stage of the disease at the time of diagnosis, nor the ability to use prospective monitoring of the surgical outcomes with a nationwide scope.

In 2016, the Polish Society of Surgical Oncology (PSSO) began collecting data on the surgical treatment of rectal cancer as part of a multi-center observational study (PSSO-01). One of the objectives of this project was to evaluate the early results of surgical treatment and to determine the proportion of patients who had a permanent intestinal stoma in long-term follow-up (up to 12 months after surgery). The purpose of this study was to provide basic data on the current surgical treatment of rectal cancer in Poland.

\section{Material and methods Study centers}

The participation of the institutions in the research project PSSO-01 was voluntary. The main criterion for the qualification of the centers was the possibility of monitoring postoperative complications within a minimum of 30 days after surgery and long-term outcomes up to 12 months after surgery. At the beginning of the study (April 2016), there were 7 registered centers. Others joined during the study. 17 out of 24 registered centers were active in the study. The activity of the centers during the study period is shown in figure 1 . The recruitment process for the study has been described in detail and published previously [1]. Taking into account the number of patients enrolled in the study from each institution, the centers were divided into three categories: high volume ( $>50$ operations per year), medium volume (25-50 operations per year), and low volume ( $<25$ operations per year). Due to the COVID-19 pandemic and the temporary interruption of the normal work of the hospitals, the volume was calculated according to the following formula: (number of patients recruited until $31^{\text {st }}$ March $2020 \div$ the time of the center's activity [in months] to the date of $31^{\text {st }}$ March 2021) $\times 12$.

\section{Population of the study}

The project of the study received the approval of the Bioethical Committee. During the study period, all patients with primary

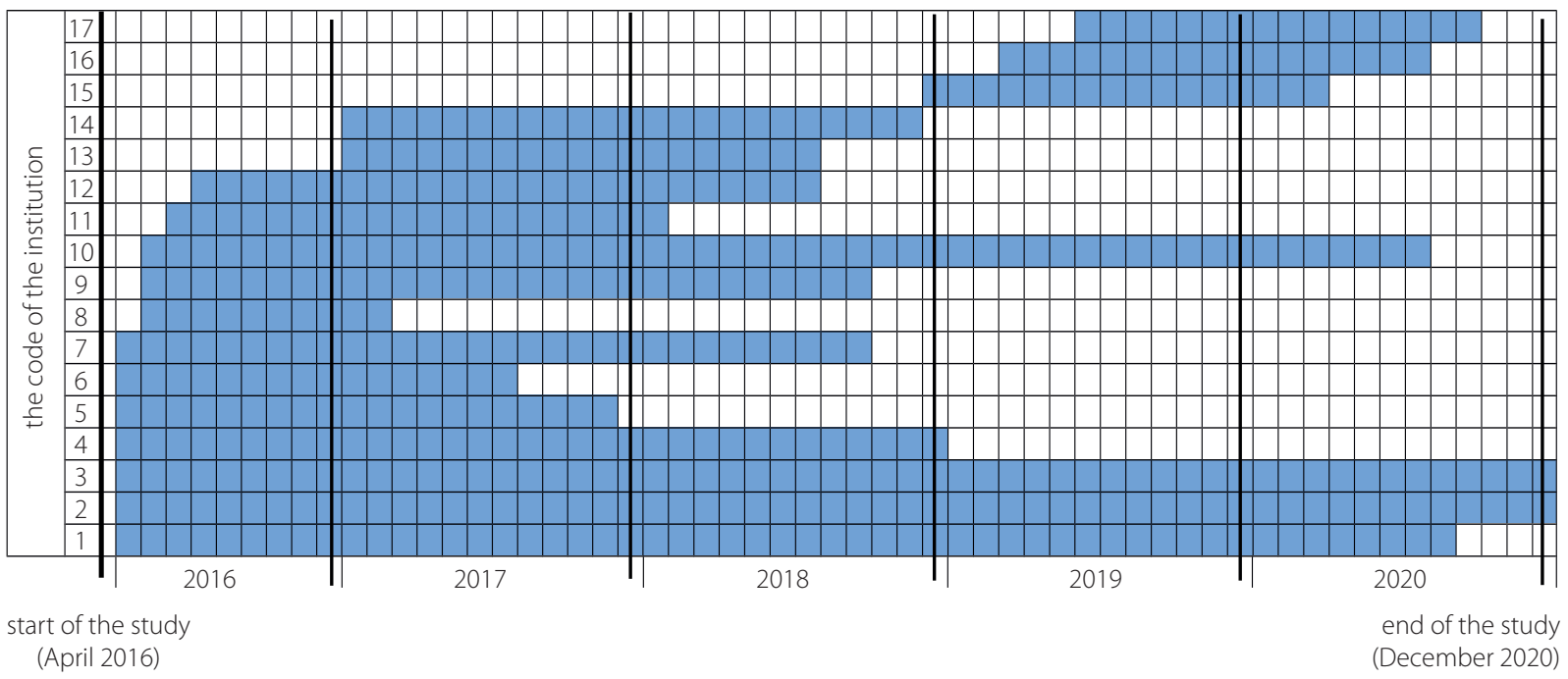

Figure 1. Activity of the centers in the study period 
rectal cancer (coded as C20, International Classification of Disease-10) operated on at the research centers were registered. The following data were prospectively collected:

- gender - distant metastases,

- concomitant diseases,

- preoperative treatment,

- technique and type of surgery, postoperative complications according to the Dindo-Clavien classification.

Because the main purpose of the PSSO-01 study focused on anastomotic leakage, wider data were collected only in the group of patients after anterior resection.

\section{Follow-up}

The data of the presence of a stoma after anterior resection was prospectively collected within 12 months from the date of surgery. If a stoma at the evaluation points specified above was still present, the reasons for this has been described. The information on bowel restoration following Hartmann's procedure was retrospectively collected.

\section{Statistical analysis}

Missing data were not defaulted to negative, and denominators reflect only actual reported cases. Summary statistics were expressed by percentages for categorial variables. Nominal variables were compared between the three groups of patients operated on at different volume centers using the chi-square test. For all tests, the statistical significance was accepted at $a=0.05$. All tests were two sided. The data were analyzed with SPSS version 19 for Windows (SPSS, Chicago, Illinois, USA).

\section{Results}

From April 2016 to December 2020, 1,607 patients undergoing surgical treatment for rectal cancer were registered. The characteristics of the patients are shown in table I. More than half of the patients (53\%; [95\% confidence interval (Cl): 49-57]) had concomitant diseases, the most common of which was hypertension 45\% (95\% Cl: 43-47). Diabetes occurred in 15\% (95\% Cl: 13-17) and ischemic heart disease in 14\% (95\% Cl: 12-16). The rate of patients with cancer spread (distant metastases) at the time of the rectal cancer diagnosis was 13\% [95\% Cl: 8-18]. Preoperative treatment of any kind was used in 920 (57\%) patients. During the operation, a stoma (permanent or temporary) was created in 890 (56\%) patients. Taking into account the patients' characteristics and their treatment, many statistically significant differences were found between the centers of different volumes - table II.

More patients with advanced cancer (metastatic disease) were operated on in the low volume centers than in high volume centers: $18 \%$ vs. $11 \%$ respectively ( $p=0.020$; relative risk (RR): 1.61 [95\% Cl: 1.10-2.35]). There was also a difference in the proportion of patients with concomitant disorders (such as ischemic heart disease, hypertension, and diabetes) who were treated in different centers: high volume centers $48 \%$
Table I. Characteristic of the study group

\begin{tabular}{|c|c|}
\hline & $\begin{array}{l}\text { Patients } \\
\text { n (\%) }\end{array}$ \\
\hline $\begin{array}{l}\text { volume of the study center: } \\
\text { - } \text { - high ( }>50 \text { operations per year) } \\
\text { - } \text { low ( }<25 \text { operations per year) }\end{array}$ & $\begin{array}{l}853(53) \\
563(35) \\
191(12)\end{array}$ \\
\hline $\begin{array}{l}\text { gender: } \\
\text { - male } \\
\text { - female }\end{array}$ & $\begin{array}{l}981(61) \\
626(39)\end{array}$ \\
\hline $\begin{array}{l}\text { metastatic disease: } \\
\text { - yes } \\
\text { - } \text { not specified }\end{array}$ & $\begin{array}{c}197(13) \\
59\end{array}$ \\
\hline $\begin{array}{l}\text { concomitant disorders: } \\
\text { - yes }\end{array}$ & $846(53)$ \\
\hline $\begin{array}{l}\text { preoperative RTH or CRT: } \\
\text { - yes } \\
\text { - no }\end{array}$ & $\begin{array}{l}920(57) \\
687(43)\end{array}$ \\
\hline $\begin{array}{l}\text { mode of surgery: } \\
\text { - urgent } \\
\text { - elective } \\
\text { - no data }\end{array}$ & $\begin{array}{c}49(3) \\
1540(97) \\
18\end{array}$ \\
\hline $\begin{array}{l}\text { abdominal approach: } \\
\text { - } \text { open } \\
\text { - laparoscopic } \\
\text { - } \text { no data or not applicable }\left(^{*}\right)\end{array}$ & $\begin{array}{c}1325(85) \\
233(15) \\
49\end{array}$ \\
\hline 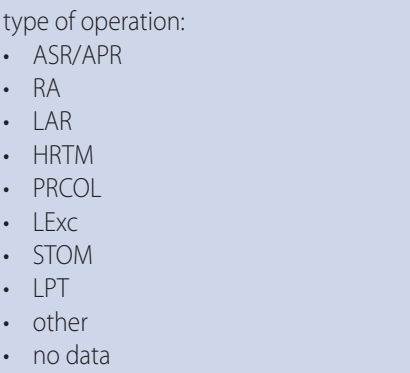 & $\begin{array}{c}341(21) \\
530(33) \\
322(20) \\
200(13) \\
5(0.3) \\
28(2) \\
130(8) \\
7(0.4) \\
28(2) \\
16\end{array}$ \\
\hline
\end{tabular}

RTH - preoperative radiotherapy; CRT - preoperative chemo-radiotherapy; ASR - abdomino-sacralis resection; APR - abdomino-perineal resection; RA - anterio resection; LAR - low anterior resection (anastomosis $\leq 5 \mathrm{~cm}$ from the anal verge): HRTM - Hartmann's procedure; PRCOL - proctocolectomy; LExc - local excision; STOM - colostomy; LPT - laparotomy; $\left({ }^{*}\right)$ - resection without laparotomy (for example: local excision)

vs. medium volume centers 57\% ( $p=0.005 ; \mathrm{RR} 1.18$ [95\% Cl: 1.06-1.30] vs. low volume centers $60 \%$ ( $p=0,006$; RR 1.24 [95\% Cl: 1.08-1.42]). Preoperative radiotherapy or chemo-radiotherapy was used in only $35 \%$ of patients operated on in low volume centers. This was less than in medium volume centers ( $p<0.001$; RR 1.52 [95\% Cl: 1.23-1.87]) and in high volume centers ( $p<0.001$; RR 1.90 [95\% Cl: 1.55-2.32]). There were also differences in neoadjuvant treatment between high volume centers and medium volume centers: $66 \%$ and 52\% respectively ( $p<0.001$; RR 1.25 [95\% Cl: 1.14-1.37]).

\section{Surgical treatment}

Emergency operations were performed more frequently in low volume centers than in medium and high volume centers ( $p<0.001$; RR 3.04 [95\% Cl: 1.67-5.53]). The rate of laparoscopic resection in medium volume centers was higher than in high volume centers (22\% vs. 13\%: p < 0.001; RR 1.70 [95\% Cl: 1.34-2.16)] 
Table II. The surgical treatment and volume of the center

\begin{tabular}{|c|c|c|c|c|}
\hline \multirow[t]{2}{*}{ Factor } & \multicolumn{3}{|c|}{ Volume of the center } & \multirow[t]{2}{*}{$p$ value } \\
\hline & $\begin{array}{c}\text { High } \\
n=853\end{array}$ & $\begin{array}{l}\text { Medium } \\
n=563\end{array}$ & $\begin{array}{c}\text { Low } \\
n=191\end{array}$ & \\
\hline $\begin{array}{l}\text { gender: } \\
\text { - male } \\
\text { - female }\end{array}$ & $\begin{array}{l}534(63 \%) \\
319(37 \%)\end{array}$ & $\begin{array}{l}331(59 \%) \\
232(41 \%)\end{array}$ & $\begin{array}{l}116(61 \%) \\
75(39 \%)\end{array}$ & 0.354 \\
\hline $\begin{array}{l}\text { concomitant disorders: } \\
\text { - yes }\end{array}$ & $412(48 \%)$ & $320(57 \%)$ & $114(60 \%)$ & 0.001 \\
\hline $\begin{array}{l}\text { clinical stage (TNM): } \\
\text { - } \text { IV (metastatic disease) } \\
\text { - } \quad \text { I-III } \\
\text { - } \text { not specified }\end{array}$ & $\begin{array}{c}94(11 \%) \\
739(89 \%) \\
20\end{array}$ & $\begin{array}{c}73(13 \%) \\
477(87 \%) \\
13\end{array}$ & $\begin{array}{c}30(18 \%) \\
135(82 \%) \\
26\end{array}$ & 0.047 \\
\hline $\begin{array}{l}\text { preoperative RTH or CRT: } \\
\text { - yes }\end{array}$ & $559(66 \%)$ & $295(52 \%)$ & $66(35 \%)$ & $<0.001$ \\
\hline $\begin{array}{l}\text { urgency of surgery: } \\
\text { - urgent } \\
\text { - elective } \\
\text { - no data }\end{array}$ & $\begin{array}{c}22(3 \%) \\
829(97 \%) \\
2\end{array}$ & $\begin{array}{c}13(2 \%) \\
540(98 \%) \\
10\end{array}$ & $\begin{array}{c}14(8 \%) \\
171(92 \%) \\
6\end{array}$ & 0.001 \\
\hline $\begin{array}{l}\text { surgical abdominal approach: } \\
\text { - } \quad \text { open (classic approach) } \\
\text { - laparoscopic } \\
\text { - } \text { no data or not applicable }\left(^{*}\right)\end{array}$ & $\begin{array}{c}725(87 \%) \\
107(13 \%) \\
21\end{array}$ & $\begin{array}{c}424(78 \%) \\
119(22 \%) \\
20\end{array}$ & $\begin{array}{c}176(96 \%) \\
7(4 \%) \\
8\end{array}$ & $<0.001$ \\
\hline $\begin{array}{l}\text { surgical procedure: } \\
\text { - } \text { ASR/APR } \\
\text { - } \text { RA } \\
\text { - } \text { LAR } \\
\text { - } \text { HRTM } \\
\text { - } \text { PRCOL } \\
\text { - } \text { LEXC } \\
\text { - } \quad \text { STOM } \\
\text { - } \text { LPT } \\
\text { - } \text { other } \\
\text { - no data }\end{array}$ & $\begin{array}{c}190(22 \%) \\
265(31 \%) \\
171(20 \%) \\
108(13 \%) \\
3(0.4 \%) \\
16(2 \%) \\
76(9 \%) \\
4(0.5 \%) \\
18(2 \%) \\
2\end{array}$ & $\begin{array}{c}116(21 \%) \\
195(35 \%) \\
126(23 \%) \\
61(11 \%) \\
1(0.2 \%) \\
9(2 \%) \\
40(7 \%) \\
2(0.4 \%) \\
4(0.7 \%) \\
9\end{array}$ & $\begin{array}{c}35(19 \%) \\
70(38 \%) \\
25(13 \%) \\
31(17 \%) \\
1(0.5 \%) \\
3(2 \%) \\
14(8 \%) \\
1(0.5 \%) \\
6(3 \%) \\
5\end{array}$ & 0.102 \\
\hline $\begin{array}{l}\left.\text { defunctioning stoma: }{ }^{* *}\right) \\
\text { - yes } \\
\text { - no data }\end{array}$ & $\begin{array}{c}138(31 \%) \\
0\end{array}$ & $\begin{array}{c}71(22 \%) \\
1\end{array}$ & $\begin{array}{c}5(5 \%) \\
1\end{array}$ & $<0.001$ \\
\hline
\end{tabular}

RTH - preoperative radiotherapy; CRT - preoperative chemo-radiotherapy; ASR - abdomino-sacralis resection; APR - abdomino-perineal resection; RA - anterior resection; LAR - low anterior resection (anastomosis $\leq 5 \mathrm{~cm}$ from the anal verge); HRTM - Hartmann's procedure; PRCOL - proctocolectomy; LExc - local excision; STOM - colostomy; LPT laparotomy; $\left(^{*}\right)$ - resection without laparotomy (for example: local excision); $\left(^{* *}\right)$ - percentage is related to the performed anastomoses

and low volume centers (22\% vs. 4\%: p < 0.001; RR 5.53 [95\% Cl: 2.72-12.05)]. There were no statistically significant differences between centers of different volume, taking into account the type of performed operations ( $p=0.102$ ). However, analysis of individual types of operations has shown that fewer low anterior resections in low volume centers were performed than in high and medium volume centers (13\% vs. 21\%: $p=0.018$; RR 1.57 [95\% Cl: 1.08-2.30]). Diverting stoma in resection with primary anastomosis was performed most often in high volume centers, and the least in low centers $(p<0.001)$ - table II.

\section{The early outcomes of surgical treatment}

Most palliative resections were performed in low volume centers (19\%), and it was a statistically significant difference in proportion to medium volume centers ( $p=0.018$; RR 1.61 [95\% Cl: 1.11-2.32]) - table III. There were no differences in palliative resections between high and medium volume centers ( $p=0.075$; RR 1,28 [95\% Cl: 0,97-1,68]). Postoperative complications was recorded in 359 (23\%) patients. Most of them occurred in medium volume centers (26\%). The difference in proportion to high and low volume centers were $26 \%$ vs. $22 \%$ ( $p=0.056$; RR 1.21 [95\% Cl: 1.00-1.47]) and 26\% vs. 18\% ( $p=0.034$; RR 1.42 [95\% Cl: 1.02-1.98]) respectively. Taking into account only serious postoperative complications (grade 3-5 according to the Dindo-Clavien Classification), the difference between medium and high volume centers was not significant ( $p=0.110$ ), but $\geq 3$ grade complications were higher in medium volume centers in relation to low volume centers ( $p=0.016$; RR 1.55 [95\% Cl: 1.13-2.12]). The rate of anastomotic leakage was similar in centers with different volume (8\%, 10\%, and 7\%). Postoperative mortality was less than $1 \%$. At the end of postoperative hospitalization, 707 (45\%) patients had a permanent end-colostomy.

\section{Persistent stoma in long term observation}

The full follow-up covered 1,243 patients. Patients who had been lost from the follow-up (death or an observation pe- 
Table III. The early outcomes of surgical treatment

\begin{tabular}{|c|c|c|c|c|c|}
\hline \multirow[t]{2}{*}{ Factor } & \multirow{2}{*}{$\begin{array}{c}\text { Total } \\
n=1607\end{array}$} & \multicolumn{3}{|c|}{ Volume of the center } & \multirow[t]{2}{*}{ p value } \\
\hline & & $\begin{array}{c}\text { High } \\
n=853\end{array}$ & $\begin{array}{c}\text { Medium } \\
n=563\end{array}$ & $\begin{array}{c}\text { Low } \\
n=191\end{array}$ & \\
\hline $\begin{array}{l}\text { type of resection: } \\
\text { - } \text { palliative } \\
\text { - radical } \\
\text { - no data }\end{array}$ & $\begin{array}{c}235(15 \%) \\
1354(85 \%) \\
18\end{array}$ & $\begin{array}{l}132(16 \%) \\
719(84 \%) \\
2\end{array}$ & $\begin{array}{c}67(12 \%) \\
486(88 \%) \\
10\end{array}$ & $\begin{array}{l}36(19 \%) \\
149(81 \%) \\
6\end{array}$ & 0.035 \\
\hline $\begin{array}{l}\text { postoperative complications: } \\
\text { - yes } \\
\text {. no data }\end{array}$ & $\begin{array}{c}359(23 \%) \\
28\end{array}$ & $\begin{array}{c}182(22 \%) \\
7\end{array}$ & $\begin{array}{c}143(26 \%) \\
15\end{array}$ & $\begin{array}{c}34(18 \%) \\
6\end{array}$ & 0.044 \\
\hline 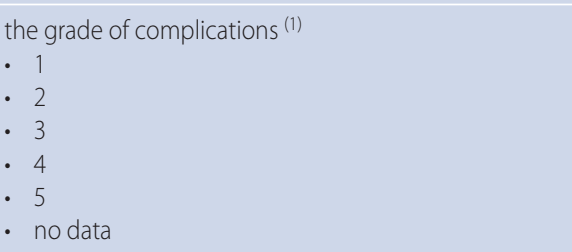 & $\begin{array}{c}72(5 \%) \\
110(7 \%) \\
129(8 \%) \\
29(2 \%) \\
14(1 \%) \\
33\end{array}$ & $\begin{array}{c}23(3 \%) \\
65(8 \%) \\
70(8 \%) \\
13(2 \%) \\
8(1 \%) \\
10\end{array}$ & $\begin{array}{c}44(8 \%) \\
38(7 \%) \\
42(8 \%) \\
13(2 \%) \\
4(1 \%) \\
17\end{array}$ & $\begin{array}{c}5(3 \%) \\
7(4 \%) \\
17(9 \%) \\
3(2 \%) \\
2(1 \%) \\
6\end{array}$ & 0.632 \\
\hline $\begin{array}{l}\text { anastomotic leakage }\left(^{*}\right) \\
\text { - yes } \\
\text { - no data }\end{array}$ & $\begin{array}{c}75(9 \%) \\
4\end{array}$ & $\begin{array}{c}36(8 \%) \\
0\end{array}$ & $\begin{array}{c}32(10 \%) \\
3\end{array}$ & $\begin{array}{c}7(7 \%) \\
1\end{array}$ & 0.607 \\
\hline $\begin{array}{l}\text { end-colostomy present at the end of hospitalization: }{ }^{(2)} \\
\text { - yes } \\
\text { - no data }\end{array}$ & $\begin{array}{c}707(45 \%) \\
46\end{array}$ & $\begin{array}{c}390(47 \%) \\
19\end{array}$ & $\begin{array}{c}234(43 \%) \\
15\end{array}$ & $\begin{array}{c}83(46 \%) \\
12\end{array}$ & 0.318 \\
\hline
\end{tabular}

$\left(^{*}\right)$ - percentage is related to the performed anastomoses; ${ }^{1}$ - according to the Dindo-Clavien Classification; ${ }^{2}$ - any surgical procedures with permanent stoma performed. Disconnection of the anastomosis due to anastomotic leakage after anterior resection and end-colostomy performed - included

riod less than 12 months) were excluded from the analysis of long-term outcomes. One year after the operation, a stoma was present in 777 (63\%) patients. In 533 (43\%) patients, it was connected with the primary type of surgery: abdomino-sacral resection / abdomino-perineal resection (ASR/APR; $n=341$ ), proctocolectomy (PRCOL; $=5$ ), palliative Hartmann's procedure (HRTM; $n=31$ ), only colostomy (STOM; $n=133$ ). In addition, in this group there were patients in whom primary anastomosis was a disconnection due to leakage, and a definitive end-colostomy was created $(n=23)$. In the remaining 244 patients, a stoma was still present because no reversal of defunctioning stoma or no bowel restorative surgery after the radical Hartmann's procedure was performed. The overall rate of bowel restorative surgery following the radical Hartmann's procedure was only $2.4 \%$. The defunctioning stoma following anterior resection (RA) or low anterior resection (LAR) was reversed in only 92 (55.4\%) patients - figure 2. The reasons for delay in defunctioning stoma reversal is shown in table IV.

\section{Discussion}

Interim analysis of the secondary purpose of the PSSO-01 study was published previously [1]. This paper reports the final outcomes based on the data of the 1607 patients enrolled in this study. Despite the large number of subjects enrolled on this trial, it should be kept in mind that the PSSO-01 project was not a registry of rectal cancer, and the results of this analysis should be treated with caution. Furthermore, the data collected during the study do not allow for detailed analysis of the reasons for the individual results of the observations. The purpose of the

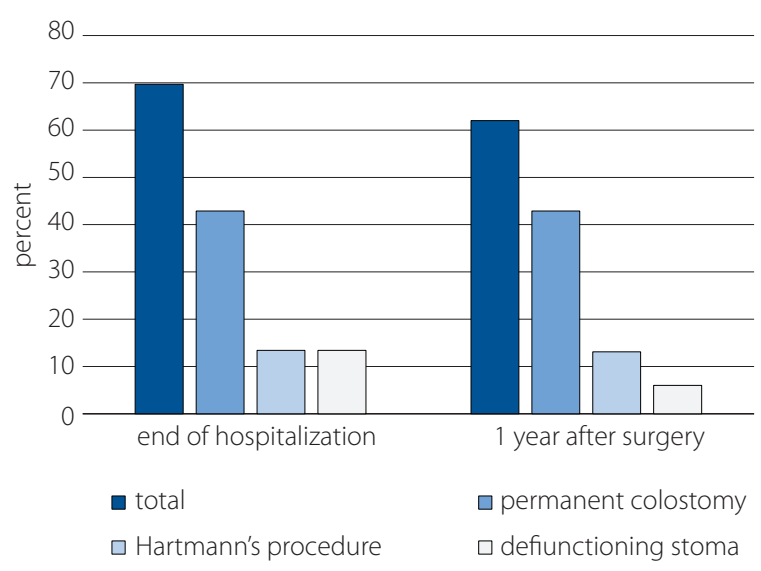

Figure 2. Persistent stoma in 1-year follow-up; analysis of 1243 patients (patients with incomplete data - excluded)

study was not to assess the quality of rectal cancer surgical treatment, but to present the current situation.

Metastatic disease at the time of rectal cancer diagnosis (stage IV according to UICC) was found in 13\% of the patients. Although some audit projects show similar data [2, 3], it must be assumed that this percentage is understated and does not reflect the actual situation. European population-based studies show that there are $22-26 \%$ of such cases [4] - table V. The actual proportion of patients in the advanced stages of the disease in Poland can reach 36-46\% [5]. The low percentage presented in the PSSO-01 study may be due to the small representation of low volume centers, where the majority of patients with advanced stages of the disease are operated on. 
Table IV. The reasons for delay in defunctioning stoma reversal (up to 12 months)

\begin{tabular}{|lc|}
\hline & $\begin{array}{c}\text { No. of patients and } \\
\text { percentage }\end{array}$ \\
\hline anastomotic leakage & $17(23.0)$ \\
\hline cancer disease progression & $9(13.4)$ \\
\hline stricture of anastomosis & $2(2.7)$ \\
\hline disagreement to restorative operations & $5(6.8)$ \\
\hline ileus of the bowel & $2(2.7)$ \\
\hline other $\left(^{*}\right)$ & $39(52.7)$ \\
\hline
\end{tabular}

$\left.{ }^{*}\right)$ - adjuvant or palliative chemotherapy, the COVID-19 pandemic and other institutional burdens

In addition, some patients with multi-metastatic disease can not be treated surgically.

Numerous European audit projects present important information on the effect of center volume on the outcomes of rectal cancer surgery. A population-based study provided in the Netherlands showed improved survival in CT4 rectal cancer patients treated in high volume centers, compared with low volume hospitals, but, after correction for neoadjuvant treatment, this difference was not statistically significant [6-8]. The criteria for dividing centers into high, medium, and small were similar to those in our study. In the Netherland's study, the overall rate of neoadjuvant radiotherapy or chemo-radiotherapy treatment was very high, and there were small differences between low, medium, and high volume centers: 89\%, 88\%, and $90 \%$ respectively. Compared to this data, the information collected in the PSSO-01 study show much lower rate of pa- tients treated preoperatively in different volume hospitals $(66 \%$, $52 \%$, and 35\%). The reason for these differences are due to the fact that the PSSO-01 study patients with a tumor in the upper part of the rectum were enrolled. However, compared to data from Denmark, England, Norway, and Sweden, the overall rate of patients receiving radiotherapy is similar [4].

A laparoscopic resection of rectal cancer was performed less frequently than in other European countries. Schnitzbauer et al. has shown that the use of laparoscopy in Germany increased constantly from 12.3\% to 48.1\% between 2007 and 2016 [9]. In the initial period of the PSSO 01 study (2016), the percentage of laparoscopic operations was only $9 \%$, but it increased somewhat to $15 \%$ after 4 years. Although this is still a small rate, the upward trend is clearly visible and can be expected to reach the same level as other European countries in the coming years. Currently, the most laparoscopic resections are performed in medium volume centers (22\%), and the least in low volume centers (4\%). Other than that, data from the Dutch centers show that the most laparoscopic operations are performed in high volume centers (59.8\%), but low volume centers perform 45.7\% [7].

The total rate of restorative rectal resection (anterior resection or low anterior resection) was 53\% (51-58\% depending on the center's volume). For Hartmann's procedure (HRTM), this was 13\% (11-17\%), and abdomino-sacral resection / abdomino-perineal resection (ASR/APR) 21\% (19-22\%). The differences between different volume centers were not statistically significant. The exception was for low anterior resection (LAR), which was performed less frequently in low volume centers than in high and medium volume centers. Data from Belgian

Table V. Rectal cancer surgery in Europe

\begin{tabular}{|c|c|c|c|c|c|c|c|c|}
\hline & Denmark & England & Norway & Sweden & Netherlands & Belgium & Germany & Poland \\
\hline $\begin{array}{l}\text { sours: } \\
\text { [refferences] }\end{array}$ & $\begin{array}{c}\text { population- } \\
\text {-based study } \\
{[4]}\end{array}$ & $\begin{array}{c}\text { population- } \\
\text {-based study } \\
{[4]}\end{array}$ & $\begin{array}{c}\text { population- } \\
\text {-based study } \\
{[4]}\end{array}$ & $\begin{array}{c}\text { population- } \\
\text {-based study } \\
{[4]}\end{array}$ & $\begin{array}{c}\operatorname{DSCA}^{(1)} \\
{[2]}\end{array}$ & $\begin{array}{c}\text { PROCARE } \\
\text { BCR }^{(3)} \text { IMA } \\
{[3]} \\
{[3]}\end{array}$ & $\begin{array}{c}\text { population- } \\
\text {-based study } \\
{[9]}\end{array}$ & $\begin{array}{l}\text { observationa } \\
\text { study } \\
\text { [PSSO-01] }\end{array}$ \\
\hline $\begin{array}{l}\text { years of data } \\
\text { collected }\end{array}$ & 2010-2012 & 2010-2012 & 2010-2012 & 2010-2012 & 2009-2011 & $2006-2008$ & $2007-2016$ & $2016-2020$ \\
\hline No. of patients & 4391 & 27599 & 3111 & 5797 & 7099 & 6353 & 23001 & 1607 \\
\hline $\begin{array}{l}\text { gender: } \\
\text { - male } \\
\text { - female }\end{array}$ & $\begin{array}{l}61 \% \\
39 \%\end{array}$ & $\begin{array}{l}64 \% \\
36 \%\end{array}$ & $\begin{array}{l}59 \% \\
41 \%\end{array}$ & $\begin{array}{l}59 \% \\
41 \%\end{array}$ & $\begin{array}{l}62 \% \\
38 \%\end{array}$ & $\begin{array}{l}60 \% \\
40 \%\end{array}$ & $\begin{array}{l}63 \%(\wedge) \\
37 \%(\wedge)\end{array}$ & $\begin{array}{l}61 \% \\
39 \%\end{array}$ \\
\hline $\begin{array}{l}\text { disease stage at } \\
\text { diagnosis: } \\
\text { - } \text { stage I-III } \\
\text { - } \text { stage IV } \\
\text { - } \text { unknown stage }\left(^{*}\right)\end{array}$ & $\begin{array}{l}75 \% \\
25 \% \\
13 \% \\
\end{array}$ & $\begin{array}{l}78 \% \\
22 \% \\
16 \%\end{array}$ & $\begin{array}{c}74 \% \\
26 \% \\
13 \%\left(^{*}\right)\end{array}$ & $\begin{array}{c}76 \% \\
24 \% \\
8 \%\end{array}$ & $\begin{array}{l}92 \% \\
8 \% \\
4 \%\end{array}$ & $\begin{array}{l}88 \% \\
12 \% \\
41 \%\end{array}$ & $\begin{array}{l}80 \% \\
20 \% \\
\text { ND }\end{array}$ & $\begin{array}{c}87 \% \\
13 \% \\
4 \%\end{array}$ \\
\hline $\begin{array}{l}\text { received } \\
\text { radiotherapy }\end{array}$ & $27 \%$ & $41 \%$ & $43 \%$ & $51 \%$ & $83 \%$ & $50 \%$ & $40 \%(\wedge)$ & $57 \%$ \\
\hline $\begin{array}{l}\text { laparoscopic } \\
\text { approach }\end{array}$ & ND & ND & ND & ND & $38 \%$ & ND & $28 \%$ & $15 \%$ \\
\hline $\begin{array}{l}\text { received resectional } \\
\text { surgery }\end{array}$ & $68 \%$ & $60 \%$ & $66 \%$ & $71 \%$ & $95 \%$ & $81 \%$ & ND & $89 \%$ \\
\hline
\end{tabular}

$\left({ }^{*}\right)$ - percentage is related to the whole study group; $(\wedge)$ - percentage is related to only UICC stage I-III, RO resection and planned operation; ND - no data; ${ }^{-}$- The Dutch Surgical Colorectal Audit; ${ }^{2}$ - Belgian multidisciplinary project on cancer of the rectum; ${ }^{3}$ - Belgian Cancer Registry; ${ }^{4}-$ InterMutualistic Agency database 
databases show a 59\% rate of sphincter saving operations, 3\% of HRTM and 17\% of ASR [3]. A population-based study from the Netherlands (based on the Dutch Surgical Colorectal Audit - DSCA) presents statistically significant differences between different volume centers by taking into account the type of surgery: more sphincter saving procedures (LAR and HRTM account together) and low ASR in high volume centers [6]. The DSCA audit showed that the total ASR percentage was 30.5\% [2], which is higher than in the PSSO-01 study. However, all this data is difficult to compare because the type of resection, such as ASR/APR or LAR, is mainly determined by the location of the tumor. For the Belgian and the Netherland's registry, patients with a tumor located in the lower and middle third of the rectum were enrolled. In our study, we included patients with primary adenocarcinoma of the rectum between 0 and $15 \mathrm{~cm}$ above the anal verge.

In our study, the overall rate of postoperative complications was higher in medium volume centers compared to high and low volume centers. Jonker et al [7] reported similar observations, although the overall complication rate was higher than in our study. The low rate of defunctioning stoma in LAR (5-31\% depending on the volume of the center) reported in our study is surprising because the data from the Netherlands show a significantly higher percentage of anastomosis with a defunctioning stoma (65.5-80.3\% depending on the hospital volume) [7]. Despite this, the rate of anastomotic leakage in PSSO-01 was similar to the population-based data of the DSCA [10]. These outcomes confirm the observations that a high tendency towards defunctioning stoma construction did not result in lower overall anastomotic leakage and the ability to select patients for stoma construction plays the most important role in the choice of optimal surgical strategy [10].

The long-term outcomes of the present study showed a high rate $(63 \%)$ of persistent stoma over the 1 year follow-up. After excluding the surgical procedures connected with permanent end-colostomy, we conclude that most of curative HRTM is a definitive surgical procedure and almost half of the defunctioning stomas are not closed following 12 months. The reasons for leaving the protective stoma allow us to assume that most of them will remain permanently. Data from DSCA has shown 54.2\% end-colostomy procedures (included ASR) [2]. It is higher than in our study (43\%). European multi-center studies present data that most diverting stoma is reversed within 12 months, but that one in four defunctioning stomas is not reversed 3 years after surgery [11-13]. Anastomotic leakage is one of the most important risk factors for not reversing stomas. A Swedish retrospective multi-center study [14] including 1442 patients undergoing anterior resection observed that the overall rate of permanent stoma among patients with anastomotic leakage was $65 \%$. The rate of definitive stoma at a level of $>60 \%$ following 12 months in our study seems to be high. However, other studies showed similar results. In a retrospective study conducted in Sweden, the permanent stoma rate was $63.2 \%$ when emergency and palliative procedures were included, and 54.9\% when only elective curative cases were considered. The authors concluded that stoma rates taken at face value may not provide an accurate picture of a particular colorectal unit's quality of care [15].

\section{Conclusions}

We are presenting the results obtained in the prospective multi-center study PSSO-01, which focused on the surgical treatment of rectal cancer. We compared our outcomes with European population-based studies. Finally, the question should be asked: are these results representative of the population of rectal cancer patients undergoing surgery in Poland? Although the study had a prospective nature, it has several important limitations. Firstly, there was the administrative burden associated with data collection. There was no monitoring of the quality of recorded data at each of the centers by an independent study office. The accurate measurement of quality of care is complex and requires the collection of multiple data points from different phases of the care process. Therefore, the dataset is limited, but still entails valid information. Secondly, PSSO-01 has a limitation regarding the possibility of selection bias since the participation of the centers in the study was voluntary. Nevertheless, different volume centers were represented in this study. Unfortunately, in comparison to data from European population-based studies, the proportion of high, medium, and low centers in PSSO-01 underrepresented low volume centers. However, the results reported by the high and medium volume centers may correspond to the actual situation.

\section{Conflict of interest: none declared}

\section{Andrzej Rutkowski}

Maria Sklodowska-Curie National Research Institute of Oncology Department of Gastroenterological Oncology ul. Roentgena 5

\section{2-781 Warszawa, Poland}

e-mail:andrzej.rutkowski@pib-nio.pl

\section{Received: 15 Aug 2021}

Accepted: 17 Aug 2021

\section{References}

1. Błaszkowski T, Celban G, Domagała M, et al. Surgical treatment of rectal cancer in Poland - a report from a prospective, multi-centre observational study PSSO_01 conducted under the auspices of the Polish Society of Surgical Oncology. Nowotwory. Journal of Oncology. 2018; 68(3): 118-126, doi: 10.5603/njo.2018.0019.

2. Leersum NJV, Snijders HS, Henneman D, et al. The Dutch Surgical Colorectal Audit. Eur J Surg Oncol. 2013; 39(10): 1063-1070, doi: 10.1016/j. ejso.2013.05.008.

3. Jegou D, Penninckx F, Vandendael T, et al. PROCARE. Completeness and registration bias in PROCARE, a Belgian multidisciplinary project on cancer of the rectum with participation on a voluntary basis. Eur J Cancer. 2015; 51(9): 1099-1108, doi: 10.1016/j.ejca.2014.02.025, indexed in Pubmed: 24726735.

4. Majano SB, Girolamo CDi, Rachet B, et al. Surgical treatment and survival from colorectal cancer in Denmark, England, Norway, and Sweden: a population-based study. Lancet Oncol. 2019; 20(1): 74-87, doi: 10.1016/s1470-2045(18)30646-6. 
5. Ciesielski P, Berut M, Górnicki K, et al. Assessment of the Surgical Treatment Results in Patients with Colorectal Cancer in a District Hospital Versus Treatment Results in a Highly Specialized Center. Pol Przegl Chir. 2016; 88(4): 188-195, doi: 10.1515/pjs-2016-0050, indexed in Pubmed: 27648619

6. Hagemans JAW, Alberda WJ, Verstegen M, et al. Hospital volume and outcome in rectal cancer patients; results of a population-based study in the Netherlands. Eur J Surg Oncol. 2019; 45(4): 613-619, doi: 10.1016/j. ejso.2018.12.018, indexed in Pubmed: 30600101.

7. Jonker FHW, Hagemans JAW, Burger JWA, et al. Dutch Snapshot Research Group. The influence of hospital volume on long-term oncological outcome after rectal cancer surgery. Int J Colorectal Dis. 2017; 32(12): 1741-1747, doi: 10.1007/s00384-017-2889-2, indexed in Pubmed: 28884251.

8. Leonard D, Penninckx F, Kartheuser A, et al. PROCARE. Effect of hospital volume on quality of care and outcome after rectal cancer surgery. $\mathrm{Br}$ J Surg. 2014; 101(11): 1475-1482, doi: 10.1002/bjs.9624, indexed in Pubmed: 25142810.

9. Schnitzbauer V, Gerken M, Benz S, et al. Laparoscopic and open surgery in rectal cancer patients in Germany: short and long-term results of a large 10-year population-based cohort. Surg Endosc. 2020; 34(3): 1132-1141, doi: 10.1007/s00464-019-06861-4, indexed in Pubmed: 31147825 .
10. Snijders HS, van Leersum NJ, Henneman D, et al. Optimal Treatment Strategy in Rectal Cancer Surgery: Should We Be Cowboys or Chickens? Ann Surg Oncol. 2015; 22(11): 3582-3589, doi: 10.1245/s10434-0154385-7, indexed in Pubmed: 25691277.

11. Gustafsson $C P$, Gunnarsson U, Dahlstrand U, et al. Loop-ileostomy reversal-patient-related characteristics influencing time to closure. Int J Colorectal Dis. 2018; 33(5): 593-600, doi: 10.1007/s00384-018-2994-x, indexed in Pubmed: 29508050.

12. David GG, Slavin JP, Willmott S, et al. Loop ileostomy following anterior resection: is it really temporary? Colorectal Dis. 2010; 12(5): 428-432, doi: 10.1111/j.1463-1318.2009.01815.x, indexed in Pubmed: 19226365.

13. Jørgensen JB, Erichsen R, Pedersen BG, et al. Stoma reversal after intended restorative rectal cancer resection in Denmark: nationwide population-based study. BJS Open. 2020 [Epub ahead of print], doi: 10.1002/bjs5.50340, indexed in Pubmed: 33022143.

14. Jutesten $\mathrm{H}$, Draus J, Frey J, et al. High risk of permanent stoma after anastomotic leakage in anterior resection for rectal cancer. Colorectal Dis. 2019; 21(2): 174-182, doi: 10.1111/codi.14469, indexed in Pubmed: 30411471.

15. Codd RJ, Evans MD, Davies M, et al. Permanent stoma rates: a misleading marker of quality in rectal cancer surgery. Colorectal Dis. 2014; 16(4): 276-280, doi: 10.1111/codi.12509, indexed in Pubmed: 24299162 